\title{
La inclusión social desde la cultura visual y las prácticas contemporáneas del arte
}

\author{
FERNANDO MIRANDA \\ SEGUNDO MOYANO
}

Resumen

Este artículo reflexiona acerca del tema de la inclusión social en programas educativos y sociales desde una perspectiva de cultura visual. Se considera el trabajo con los contenidos del arte contemporáneo y sus posibilidades educativas incluyendo nuevas prácticas en el espacio público y el lugar de las tecnologías.

Palabras clave:

Cultura visual, inclusión social, arte contemporáneo 


\title{
Social inclusion from visual culture: practices and technologies
}

\author{
FERNANDO MIRANDA \\ SEGUNDO MOYANO
}

Abstract

This article reflects on the social inclusion in social and educational programmes since a visual culture perspective.

Keywords:

Visual culture, social Is considered the work with contemporary art resources and the educative possibilities including new practices in public inclusion, contemporary art space and the place of technologies. 
La actualidad, posiblemente, nos convoca a pensar y repensar algunas de las cuestiones que han venido delimitando hasta ahora el campo de la educación, especialmente cuando nos referimos a cuestiones sociales y culturales.

En lo que respecta a la educación social, afirmábamos en otro momento (MOYANO, 2009) que coexisten planteamientos, fundamentalmente, en dos grandes direcciones: en primer lugar, una educación social orientada, en su mayor parte, a la ayuda social de los individuos, fijada al adjetivo social y con tendencias a pensar lo educativo tan sólo como elemento agregado a un trabajo social compensatorio más amplio que incluiría cuestiones relacionadas con lo emocional, la contención y la prevención social; y, en segundo lugar, una educación social que plantea lo educativo como constitutivo del concepto, que apuesta por la educación como eje principal de las prácticas que se desarrollan en este campo. Es decir, una propuesta de carácter fundamentalmente pedagógico ${ }^{1}$ que permite la articulación de los individuos con las exigencias sociales de época. La educación, en este sentido, se convierte en el pivote configurador de la educación social y no en un elemento más. Esos posicionamientos teóricos abarcan perspectivas distantes entre sí, fruto de tradiciones diferenciadas y con fines que, si bien podrían converger en algún postulado, difieren en el lugar otorgado a la educación.

Del mismo modo, las referencias parecen casi que repetirse respecto al espacio de la educación artística. Es aún predominante, en general, la idea de lo educativo en el arte con impactos y desarrollos puramente afectivos, cuando mucho (auto)expresivos, y propios de una condición más íntima de los sujetos.

Por esto, pensar los límites actuales de la educación comporta abrir otras posibilidades. Es decir, tomar el límite como 
posibilidad, con la finalidad de afrontar esas nuevas aperturas a modo de prevención contra lo previsible de las prácticas de la educación. En esta búsqueda de nuevos puestos fronterizos, nos topamos con dos grandes límites: por un lado, con las dificultades que se generan para sostener la demanda actual en el campo de la educación que contenga la idea de trabajar en torno a la inclusión social; y, por otro lado, la desorientación acerca de propuestas educativas con valor social, buscando, si ha lugar, campos de acción diferentes.

Ambos asuntos se encuentran atravesadas por lo que Giorgio Agamben define como la oscuridad de la contemporaneidad: "Todos los tiempos son, para quien experimenta su contemporaneidad, oscuros" (2011, p. 21). Este aspecto subyuga, en ocasiones, la emergencia de propuestas socioeducativas alternativas, digamos, a las que denominaríamos como tradicionales, habituales y/o previsibles.

Ahora bien, si aún nos conducimos en las palabras de Agamben, esa oscuridad a la que apela no está planteada en términos de pasividad sino que, más bien, "equivale a neutralizar las luces provenientes de la época para descubrir su tiniebla, su especial oscuridad, que no es, sin embargo, separable de las luces" (AGAMBEN, 2011, p. 21).

La demanda actual respecto de las prácticas educativas en lo social y con las imágenes, así como el encargo social que las sostiene -y que se canaliza en instituciones de diferente carácter y por profesionales de distintas formaciones-, se encuentra, en tiempos de crisis, en trámites de desborde.

Si bien el desafío de la inclusión social ha existido a lo largo del recorrido de la educación siempre ha habido una deriva hacia concepciones basadas en el control y la prevención. Las condiciones sociales actuales radicalizan a veces las acciones en torno a estas cuestiones, desmembrando las posibilidades de actuación social y pedagógica de los profesionales de la educación social y/o de la educación artística.

En educación social esto es muy claro pues comporta un quiebre en la perspectiva y en la acción: el encargo de las políticas sociales de los años '8o y ' 90 del siglo XX se sustentaba en una doble dimensión de atender y educar a los sujetos en situación de dificultad social. Fruto de la coyuntura actual, el giro que opera dirige ese encargo a la atención en situaciones sociales en ocasiones de extrema dificultad.

De ahí también que emerja, entonces, una cierta desorientación de las prácticas en términos de ubicar lo educativo de las propuestas dirigidas a la inclusión social y primen las 
condiciones del control o el vaciamiento de los contenidos educativos. A esta cuestión, además, se añaden planteamientos que no en pocas ocasiones esconden una incapacidad de asumir una reinvención y actualización de aportaciones al trabajo educativo en el campo social.

Sin embargo, retomemos la articulación entre límite y posibilidad, donde ésta última aparece como desconocida, como territorios a explorar tras la cerca del límite. La finalidad de poder cruzar al otro lado radica en la necesidad de, por una parte, revitalizar las propuestas educativas y, por otra, establecer la asociación con otras agencias sociales, culturales, artísticas, tecnológicas, que provoquen ampliaciones epistemológicas de los discursos que sostienen las prácticas educativas, así como otras formas de caracterizar e implementar proyectos y acciones sociales.

\section{Las condiciones de lo artístico en la contemporaneidad}

El subtítulo no trata de establecer una crítica del arte contemporáneo o de las prácticas actuales de producción creativa, el debate en este sentido es amplio y trasciende nuestro cometido. Lo que si parece que se requiriera es establecer cómo creemos que se constituye el contexto general en que actuamos como académicos, artistas o educadores cuando nos referimos a las imágenes visuales y a las artes.

Formar un necesario posicionamiento en este punto, aún en la necesidad de su condición provisoria y en su posibilidad de revisión, nos ayudará a producir mejores alternativas respecto a las proposiciones teóricas y de acción que asumamos.

Es desde el sitio de cada uno desde donde debe partir el camino de analizar, decidir y actuar. En definitiva, encontrar alternativas para cruzar los límites de la actualidad, atravesar espacios y crear nuevas condiciones de acción. A eso en realidad refiere, insistimos, lo contemporáneo.

Nos toca volver a coincidir con Giorgio Agamben en cuanto a qué supone que es ser contemporáneo. Así "contemporáneo es aquel que percibe la oscuridad de su tiempo como algo que le incumbe y no cesa de interpelarlo, algo que, más que cualquier luz, se dirige directa y singularmente a él" (2011, p. 22). Ante este sentido que Agamben otorga al hecho de ser contemporáneo, señalar los límites actuales de la educación (como una suerte de oscuridad) permite entornar algo de sus posibilidades como algo que nos cierne y 
nos interpela. Así, tanto en el sostenimiento de la demanda como en la producción de propuestas educativas, se justifica y significa un acto de contemporaneidad.

La época en que vivimos ha multiplicado los repertorios de la cultura visual, y particularmente aquellos construidos desde los espacios del arte, la comunicación corporativa, y la publicidad, en otras tantas diversas e impensadas localizaciones sociales, culturales y también, económicas.

Estos repertorios, si bien la mayoría de las veces están mediados por artefactos tecnológicos de progresivo desarrollo son, a la vez, de mayor facilidad de acceso y uso y, por tanto, de penetración cotidiana en los múltiples espacios en que nos constituimos como sujetos individuales.

Aún aquellas imágenes que podríamos ubicar en lo que se ha de nombrar como el gran catálogo del arte contemporáneo ha visto multiplicar su densidad y complejidad. Somos espectadores de una suerte de hiperproducción visual que se vuelve altamente problemática cuando existe la sensación extendida de confusión acerca del valor y la condición de las imágenes, y en particular de las que definiríamos como obras artísticas.

Estamos, además, colocados en un punto casi permanente que nos refuerza la duda acerca de la condición de la imagen artística como tal, salvo por la tranquilidad que nos brinda su firma de autoría o su lugar de exhibición o distribución.

De cualquier forma, leemos en la prensa noticias reiteradas que nos conducen a reforzar el convencimiento de que, a juzgar por acontecimientos recientes, la institucionalidad del arte consagrado sigue sin brindar las garantías de pertenencia de la imagen ${ }^{2}$. Y aún así debemos seguir trabajando y pensando la educación artística y reafirmándonos en la ruptura del canon.

Es aquí también que se expresa la misión que tenemos como educadores en la contemporaneidad:

Pertenece en verdad a su tiempo, es en verdad contemporáneo, aquel que no coincide a la perfección con éste ni se adecua a sus pretensiones, y entonces, en ese sentido, es inactual; pero, justamente por esto, a partir de ese alejamiento y ese anacronismo, es más capaz que los otros de percibir y aferrar su tiempo. (AGAMBEN, 2011, p. 18)

Desde esta definición de época, y tal como señalamos en este texto, algunas de las formas habituales de la educación -y en particular de la educación artística y de la educación so- 
cial- no nos dan la idea de haber comprendido los cambios del campo de las artes visuales y de las tecnologías ni de estar produciendo alternativas acerca de qué hacer en estos tiempos.

En el contexto actual, las imágenes, las acciones y los artefactos de todo tipo con los que las artes visuales despliegan su catálogo actual ya han consolidado definitivamente el tránsito hacia la perdida del aura de la obra de arte, la solemnidad institucional de los museos y la credibilidad de

Tal ocurrencia anunciada premonitoriamente por Walter Benjamin (2004) a principios del siglo XX y lúcidamente analizada por José Luis Brea (1991, 2002, 2003) desde la década de los años '9o, parece ser parte de la condición compartida de hoy, de nuestra oscuridad y de nuestras posibilidades de luz.

Además, y en este contexto, si consideramos la relevancia de asumir los asuntos relacionados con la inclusión social debiéramos referirnos a la construcción de nuevos vínculos y maneras de ligazón de las personas en sus entornos -aquello que Félix Guattari (200o) denomina como nuevas ecosofíasconsiderando los asuntos colectivos respecto de los intereses del sujeto de la educación; o que, en otro sentido Nicolas Bourriaud definiría como de sujetos "radicantes".

Radicantes (BOURRIAUD, 2010) o rizomáticos (DELEUZE y GUATTARI, 2008) sigue siendo necesario relevar que los vínculos y relaciones de los sujetos con lo social no son exclusivamente racionales ni una opción de conveniencia o lógica, la educación en contextos de proyectos que se orienten a la inclusión social tiene el desafío principal de producir nuevas formas de experiencia integral, que incluyan significados, sentido, sensibilidad y estética. Y allí es donde las condiciones actuales de lo visual se juegan definitivamente.

El educador ha de ser, entonces, alguien que incorpora e integra, mediante la posibilidad de la construcción narrativa, experiencias estéticas que consideren lo afectivo y lo emocional pero también lo conceptual y lo sensible. Procurar estas formas de experiencia es rehacer las prácticas culturales -entre ellas las educativas- desde el derecho de acceso a lo común pero sin desconocer las pertenencias particulares.

Tal como sostiene Imanol Aguirre (2010):

Frente a tratar las obras de arte o los eventos artísticos como obras, me gusta más tratarlas como textos, en el sentido literal de la palabra. Es decir, como tejidos, como tramas de significación, donde se articulan y concitan todas estas circunstancias de tipo cultural, histórico y social. (AGUIRRE, 2010, p. 68) 
Sirva el siguiente ejemplo. En 2011, el museo Guggenheim de la ciudad de Bilbao realizaba la exposición "Proyecto Penske (Penske Work Project)" (1998) del artista Gabriel Orozco (México, 1962) ${ }^{3}$. La sala destinada a tal fin reunión un conjunto ordenado de esculturas espontáneas, realizadas con elementos desechados por habitantes de la ciudad de Nueva York, que Orozco levantara con un camión alquilado a la compañía Penske.

Además, se completa la muestra con la serie de veintiuna fotografías instantáneas que dan cuenta de cada escultura en la proximidad de los momentos y lugares de los que han sido levantados los materiales.

En el centro de la sala, se exponen 3 baldes de pintura con una pequeña sección lateral que el artista ha hecho a cada uno. Están colocados unidos a partir de esas secciones de manera que, mirados desde arriba, la forma final es similar a un trébol de la baraja francesa.

Un visitante pasa a nuestro lado y dice:

Bueno, por lo menos en ésta se ha tomado el trabajo de hacer algo. Ha tenido que cortar los baldes.

No entraremos en la consideración de las concepciones acerca de las artes visuales que respaldan tal comentario -por demás espontáneo y sugerente a la vez-. Nuestro desafío ha de tener que ver con cómo favorecemos que los sujetos construyan sus propias elaboraciones de sentido respecto de aquellas "tramas de significación”, trascendiendo el valor otorgado a la manipulación del material y a la evidencia aparente de la obra.

\section{El interés de las artes visuales como contenidos educativos}

Para profundizar nuestro análisis, otorgamos aquí cierta razón a Mateu Cabot (2007) con relación a que la mayor asunción de la libertad creativa (agregaríamos, al menos visible y aparente) y la multiplicación casi ilimitada de medios, materiales y formatos, ha venido transformando la posibilidad de la experiencia estética.

Al mismo tiempo, sin embargo, pareciera que las posibilidades de la relación de la gente con tales producciones visuales y artísticas sigue condicionada por una suerte de paradigma pre-moderno que busca, en los materiales y en las 
propiedades sensoriales de los productos creativos, la explicación segura y confirmada de lo artístico.

Por esto, la sensación general es que la educación parece insistir la mayoría de las veces (lo hemos dicho al comienzo de este texto), en enfatizar lo artístico desde un punto de visto histórico y cerrado, lo que configura un reforzamiento de las distancias existentes entre la producción contemporánea y las posibilidades de visionado, protagonismo y acción de las personas.

Los repertorios de cultura visual de nuestra época incluyen a las realizaciones artísticas o las referencian en un lugar importante y destacado, especialmente en una serie de transacciones constantes entre los intereses del campo del arte y los de otros espacios sociales (v.gr. políticos, económi$\cos$ ), pero parece cierto también que quizás aquello que pudiéramos ubicar como propiamente artístico ha relativizado su importancia respecto a lo que podría ser su misión de antaño de condensar en exclusividad la condición estética de época y, eventualmente orientarla.

En el discurso y en la práctica, la llamada estetización de la vida cotidiana conduce frecuentemente a pensar que nuestras vidas están relacionadas con unas maneras espectaculares de ocurrencia de lo cotidiano, dominadas por la ficción guionada y por las especulaciones corporativas globalizadas y eventualmente alienantes.

Sin ignorar una cierta razón que pudiéramos otorgar a posiciones de este tipo, preferimos pensar la alternativa desde la utilización de las imágenes y los contenidos de las artes visuales en su postproducción educativa, tal como lo señalamos en este texto.

Para Aurora Fernández Polanco (2005), por ejemplo,

... no podemos dejar de considerar que los artistas anticipan, que su obra es también premonitoria. El artista hace uso de la imaginación y ello porque se propone una muy peculiar mimesis. [...] el artista se preocupa de lo desemejante, de lo diferente, lo disímil, lo discrepante. (FERNÁNDEZ POLANCO, 2005, p. 129)

Más allá de esto, hay que advertir el riesgo de que la posibilidad de hacer ver de lo artístico, especialmente cuando se vincula a lo educativo y a ciertos temas - hasta no hace muchos años considerados marginales como la condición del otro, la diferencia y las migraciones, o los asuntos de género y 
de sexualidad -, no se banalice o se instrumentalice de forma tal que impida una función transformadora del sujeto (aprendizajes) y del entorno (prácticas sociales).

Para esto, lo educativo debería también ocurrir en la relación con el conjunto de recursos vigentes respecto de la temporalidad del proyecto, de manera de que la extensión de la colaboración alcance a distintas instituciones culturales y sociales.

Las posibilidades ficcionales del arte, la construcción de narrativas inéditas (no realizadas) e insólitas (no acostumbradas) son, en efecto, parte principal de las mejores alternativas de construcción de los contenidos de las artes visuales respecto de sus posibilidades educativas y sus entornos prácticos.

Para citar sólo dos casos que podrían sernos de utilidad para explicar esta posición remitiremos, por un lado, a Edgar Endress (Chile, 1970) quien incorpora en varios de sus trabajos la relación con el poder y el abordaje de contextos sociales y políticos como referencias de sus trabajos (v.gr. "La procesión", 2001) asociando narrativamente, por ejemplo, una procesión religiosa con un desfile militar de la época de la dictadura en su país.

Un segundo ejemplo lo constituye la película de Philippe Parreno y Douglas Gordon (2006) "Zidane, un retrato del siglo XXI”. En abril de 2005, en el estadio Santiago Bernabéu de Madrid los realizadores, con más de quince cámaras, realizaron el seguimiento de un solo futbolista en el campo: Zinedine Zidane.

Esta forma particular de retrato implica captar los gestos, los movimientos, las posiciones corporales, las decisiones en el campo, de un único actor; exacerbando quizás el hecho de que las miradas se concentran en éste como principal atractivo de un juego.

Pero, en estas condiciones y más allá del análisis formal o estético, el caso a de servirnos para la posibilidad de preguntarnos: ¿Cuál es la representación que tenemos del éxito personal? ¿Qué elementos se enaltecen y cuáles se ocultan? ¿Cómo se arma la imagen del ídolo? ¿A qué otras cosas se asocia esa imagen? ¿Qué tiene que ver todo esto con valores, actitudes, logros, marcas comerciales, condiciones políticas, situaciones sociales, realidades locales?

Para Simon Critchley: "Al nivel más evidente, Zidane es un retrato del siglo 21, en el que la realidad tiene esa calidad completamente mediada. [...] Zidane es un espectáculo." (CRITCHLEY, 2009, p. 133) Pero también es una referencia a olores y sonidos que tienen que ver con el juego y con la experiencia referida al "directo" del espectáculo. 
Nos ubicamos, además, en unos contextos fundamentalmente urbanos de las prácticas educativas (v. gr. Uruguay tiene un $95 \%$ de población urbana), con todo lo que esto tiene actualmente de centralidad pero también de periferia. Algo que se traduce en ubicaciones y relaciones de tipos espaciales pero también intersubjetivas y grupales, económicas y comunitarias.

Lo urbano, la ciudad como tal, es un espacio de intervención y producción visual que transcurre de la comunicación a la estética, de lo comercial a lo social, de lo corporativo a lo político.

Abordar las posibilidades de las artes visuales contemporáneas para la inclusión social, considerando aquellos elementos que constituyen la diversidad de la trama urbana, se adscribe al concepto de cultura no ya como una cosa objetivable o un bien de propiedad de una sociedad o grupo, sino de una forma relacional y subjetiva. El objetivo educativo ha de orientarse en las maneras de establecer cómo las diferencias se ponen en juego para articular la convivencia colectiva desde las identidades que marcan también cómo se configuran los otros. Lo cultural es el espacio que traduce los acontecimientos del territorio urbano en términos de representación y significado. Y es también donde los contrastes, comparaciones y asimilaciones, definirán la negociación entre pertenencias diversas, dando paso a nuevos procesos sociales y nuevas orientaciones de sentido.

De tal forma, uno de los cometidos de las prácticas socioeducativas que tengan en cuenta la inclusión social debería ser colaborar a retejer lo social reconociendo la producción de "graves desgarramientos en la conformación tradicional de los espacios habitados. Las ciudades se han ido extendiendo más y más, y se ha creado un desbordamiento suburbial que ha tenido como consecuencia la destrucción del tejido urbano y social..." (CORTÉS, 2010, p. 123)

La alternativa de la planificación urbana ha sido muchas veces una respuesta de segregación, como denuncia el propio Cortés se han generado situaciones en que el "control arquitectónico de las fronteras sociales se ha convertido en el verdadero espíritu de la reestructuración urbana, del mismo modo que la seguridad residencial y comercial ha conseguido reemplazar las esperanzas de cualquier reforma de integración social." (CORTÉS, 2010, p. 129)

En un texto anterior (MIRANDA, 2009) publicado a partir del trabajo del colectivo alonso+craciun ${ }^{4}$ hemos señalado las posibilidades educativas del trabajo en la ciudad con las artes visuales. Pedíamos entonces ampliar la mirada sobre las cues- 
tiones desapercibidas de un territorio que creíamos conocido, buscar la llamada de atención desde la imagen, registrar los detalles visuales que surgen en nuestros entornos, combinar el uso de las tecnologías de acuerdo a una finalidad establecida, crear nuevas maneras de relacionarse con la ciudad y el contexto. Lo importante es que estas nuevas maneras contengan el potencial de explicar las formas (nuestras y de los otros) de ver el mundo en su relación con las imágenes.

En los últimos tiempos la tendencia parece haberse orientado en contrario y la evolución de la planificación y la construcción de la ciudad ha sido, en muchos casos, de segregación. Explicita Cortés que:

[el desarrollo de] estas políticas del espacio acentúa las desigualdades y la marginación social, al tiempo que imposibilita la capacidad de integración y de manifestación cultural de los diferentes sectores de la población. Con estas actitudes se acaba no sólo con la calle como lugar de encuentro y de relación de los ciudadanos, sino que se acaba también con la 'multitud', entendida ésta como la mezcla heterogénea y diversa de colectividades culturales, étnicas y de género distinto. (CORTÉS, 2010, p. 123)

Por eso, sostenemos que el logro de estas posibilidades ha de llevarse a cabo junto con la reconstitución y el reintegro social de los espacios públicos, de los sitios efectivos de convivencia y negociación de diferencias y acuerdos.

\section{Aportaciones para el abordaje de la inclusión social}

Desde las ideas de inclusión social, de acceso y relación duradera con el uso y disfrute de los bienes culturales, y de restitución y construcción de espacios públicos de relacionamiento social, el lugar de las artes visuales debe ser transformado en clave educativa desde la perspectiva de trabajo de la cultura visual. Los contenidos han de ser vueltos a enfocar, puestos en relación, narrados en nuevos guiones y secuenciados en mezclas inéditas de nuevos sentidos.

Imágenes visuales, obras artísticas y artefactos tecnológicos se convierten en la materia a transformar en sentido y significado para crear nuevas narrativas respecto de temas, situaciones y condiciones que afectan, de una u otra manera, la vida de las personas y significan y explican el mundo. 
Ha de darse por admitido que la posibilidad de teorizar sobre lo educativo y sobre las instancias y condiciones de la inclusión social -cuando se trata de los contenidos de las artes visuales y del uso de las tecnologías-, debe ser realizada considerando que tales contenidos ya no son más de lo mismo en nuevos soportes, sino verdaderamente nuevos objetos y nuevos entornos de aprendizaje.

La inclusión social tiene que considerar efectos de posibilidad real respecto de la apropiación de las tecnologías y la posibilidad de acción y de agencia. Siguiendo a Henry Giroux (2004) en este punto entendemos la agencia como la condición de ser parte activa en una fuerza de integración social; como la participación en la construcción de todo aquello que constituya los mecanismos cotidianos que produce formas de orden social.

Puede ya afirmarse con tranquilidad que el campo de la cultura no ha de ser solamente mirado desde la disponibilidad para una transmisión, sino que es un espacio participado, de intereses comunes -y también de desacuerdos y distancias- donde especialmente los niños, las niñas y los adolescentes están habituados de muchas maneras a producir -y también a consumir, usar y rechazar- significados y orientaciones de sentido, desde el uso de las tecnologías y la producción de imágenes visuales. En fin, de ejercicio de aquella idea de agencia que referimos.

Por tanto, lo que estamos promulgando es la oportunidad y necesidad de desarrollar programas, proyectos y acciones dirigidos a la inclusión social, en los que los contenidos de las artes visuales contemporáneas -sus temas, sus prácticas creativas, sus formas de acción, su oscuridad y su haz de luz- se constituyan como alternativa para facilitar procesos efectivos de participación

Asumimos la idea de inclusión social desde una realidad compleja cuya lectura lineal parece, en ocasiones, admitir como inexorable la falta de horizontes de movilidad por parte de una gran cantidad de personas, especialmente niños, niñas, adolescentes y jóvenes, que hoy están bajo unas denominadas demarcaciones de pobreza o tienen unos orígenes familiares y geográficos que los ubican como los otros. Grupos de personas que son objeto habitual de una diversidad de políticas estatales y públicas, sin que se establezca claramente que no sólo es preciso ser asistido respecto de necesidades y servicios básicos, sino que han de generarse las maneras que permitan ejercer el efectivo derecho a la ciudadanía, incluyendo una estructura social que garantice una condición cultural diversa. 
No se trata de diseñar dispositivos generales que intenten abarcar a todos por igual, sino trabajar de manera complementaria para poder comprender realidades y facilitar accesos, para construir lugares de experiencias que permitan modificar condiciones locales y comunitarias, en los espacios vitales más inmediatos, a la vez que puedan articularse en niveles de convivencia y participación mayores de transformación colectiva.

No intentamos depositar en la cultura -o, en particular, en las prácticas educativas o artísticas- una misión de salvamento social, sino articular sus contenidos como forma de fortalecer los procesos de acceso a los bienes culturales, claro está, pero también a la posibilidad de generarlos.

Ya adelantaba Richard Hamilton en una conferencia en el año 1960, reproducida en una edición reciente:

Una cultura ideal es, según mi punto de vista, aquella en la que la conciencia de su condición sea universal. Una cultura en la que todos y cada uno de sus miembros acepte la conveniencia de que haya distintos valores para distintos grupos en distintas ocasiones, en la que el artista se aferre a sus valores y dé lo mejor que pueda ofrecer a quien pueda recibirlo sin mojigatería y con buen humor, afrontando al mismo tiempo su situación histórica con sinceridad. (HAMILTON, 2010, p. 29)

La búsqueda de la democracia cultural no tiene que ver con la inclusión como intento de homogeneización sino con reconocer al otro partiendo de una diferencia que respete y garantice sus derechos. La educación artística no puede renunciar a este desafío ni obviar esta responsabilidad.

\section{Referencias}

AGAMBEN, Giorgio. Desnudez. Barcelona: Anagrama, 2011

AGIRRE, Imanol. Conceptualización de experiencia estética y educación artística In: AA.VV. Grupo de trabajo sobre educación y práctica artística. Sesiones comentadas. Valladolid: Museo Patio Herreriano - Departamento de Investigación y Educación, 2010 ."Hacia un nuevo imaginario para la educación artística" ponencia presentada al Congreso internacional de educación artística y visual ante el reto social. Cultura y territorialidad en la investigación en educación artística. Sevilla, 2006. Disponible en: http://files.myopera.com/ 
doctoradoimanol/RECURSOS/Aguirre.HaciaImaginario. doc. Acceso: 27.12.2011

BENJAMIN, Walter. Sobre la Fotografía. Valencia: Pre-Textos, 2004

BOURRIAUD, Nicolás. Postproducción. Buenos Aires: Adriana Hidalgo Editora, 2007

.Estética relacional. Buenos Aires: Adriana Hidalgo Editora, 2006

BREA, José Luis. El tercer umbral. Estatuto de las prácticas artísticas en la era del capitalismo cultural. Murcia: CENDEAC, 2003

. La era postmedia. Acción comunicativa, prácticas (post)artísticas y dispositivos neomediales. Salamanca: CASA, 2002

. Las auras frías. Barcelona: Anagrama, 1991

CABOT, Mateu. Más que palabras. Estética en tiempos de cultura audiovisual. Murcia: CENDEAC, 2007

CORTÉS, José Miguel G. La ciudad cautiva. Control y vigilancia en el espacio urbano. Madrid: Akal/Arte Contemporáneo.

CRICHTLEY, Simon. Un Dios o una marioneta -sobre Zidane de Philippe Parreno In: Estudios Visuales № 6, enero de 2009, pp. 131-137

FERNÁNDEZ POLANCO, Aurora. Historia, montaje e imaginación: sobre imágenes y visibilidades. en BOZAL, Valeriano. Imágenes de la violencia en el arte contemporáneo. Madrid: A. Machado Libros, 2005

GIROUX, Henry A. The abandoned generation. Democracy beyond the culture of fear. New York: Palgrave Macmillan, 2004

GUATTARI, Félix; DELEUZE, Gilles. Rizoma. (Introducción). Valencia: Pre-Textos, 2010

GUATTARI, Félix. Las tres ecologías. Valencia: Pre-Textos, 2000

HAMILTON, Richard. Proposiciones. Barcelona: MACBA-UAB, 2010

HATZFELD, Marc. La cultura de los suburbios. Barcelona: Laertes, 2007

HERNÁNDEZ, Fernando. Espigador@s de la cultura visual. Otra narrativa para la educación de las artes visuales. Barcelona: Octaedro, 2007

MARTINS, Raimundo. Narrativas visuais: imagens, visualidades e experiência educativa. In: VIS v. 8 no janeiro/junho de 2009 pp. 33-39 
MIRANDA, Fernando. Corolarios breves para Monsieur Pincel In: PÚBLICO \#2 Proyecto Educativo, 2009 Disponible en:

http://www.alonso-craciun.net/proyectos/publico/otros/ PUBLICO_2.pdf Acceso: 27/12/11

MOYANO, Segundo. Educación Social y ejercicio profesional. In: AA.VV. Educación Social. Acto político y ejercicio profesional. Montevideo: ADESU-MEC, 2009

NOTAS

1. Sostenemos que en educación, la Pedagogía es la disciplina de referencia, si bien no podemos entender el trabajo educativo sin la conexión y conversación con otras disciplinas que fundamentan, aportan y confluyen en el quehacer pedagógico de reflexión y análisis de los actos educativos.

2. El períodico español El País, titula en una nota recienta sobre la aparición de varios pollock falsos: "Timo de alto nivel en la cúspide del arte". La noticia completa puede accederse en la versión digital, disponible en: http://www.elpais.com/articulo/cultura/Timo/alto/nivel/cuspide/arte/ elpepicul/20111226elpepicul_1/Tes Acceso 27/12/11.

3. Disponible en: http://www.guggenheimbilbao.es/microsites/the_luminous_interval/secciones/obras_destacadas/penske_work_project. php?idioma=es Acceso: 27/12/11

4. Disponible en: http://www.alonso-craciun.net/proyectos_publico.htm Acceso: 27/12/11

Recebido em: 02/03/12

Aceito em: 20/03/12 


\section{FERNANDO MIRANDA \\ fmiranda68@gmail.com}

Doctor en Bellas Artes - Educación Artística (Facultad de Bellas Artes

- Universidad de Barcelona - España). Licenciado en Ciencias de la Educación (Universidad de la República - Uruguay). Profesor Titular e Investigador del Instituto "Escuela Nacional de Bellas Artes" de la UdelaR - Uruguay; coordina desde su creación en 2005 el Núcleo de investigación en "Cultura Visual, educación y construcción de identidad". Ha integrado en carácter de miembro titular las Comisiones Sectoriales de Enseñanza (CSE) (2004-2008) e Investigación Científica (CSIC) (2008-2012) de la Universidad de la República. Es miembro investigador del grupo de pesquisa en "Cultura Visual e Educaçao" de la Facultad de Artes Visuales - Universidade Federal de Goiás)

\section{SEGUNDO MOYANO}

\section{segunmoyano@gmail.com}

Doctor en Pedagogía (Universidad de Barcelona - España) y educador social. Profesor de la Universitat Oberta de Catalunya. Director del Grupo de Investigación Laboratorio de Educación Social. Colaborador en diversas publicaciones pedagógicas y autor de libros como Acción educativa y funciones de los educadores sociales (2012); y coordinador, junto con Jordi Planella, de Voces de la educación social (2011). Codirector de las colecciones Manuales de la Educación Social y Laboratorio de Educación Social de la Editorial UOC. 